УДК 004.9:502.521:502.13

\title{
СОСТОЯНИЕ И ПУТИ РАЗВИТИЯ ИНФОРМАЦИОННОГО ОБЕСПЕЧЕНИЯ ОХРАНЫ ЗЕМЕЛЬНЫХ РЕСУРСОВ
}

\author{
(C) 2012 г. O. A. Ткачева*, C. A. Tарасов** \\ *Новочеркасская государственная мелиоративная академия \\ **Новочеркасский колледж промышленных технологий и управления
}

Рассматриваются вопросы современного состояния планово-картографического материала, данных почвенных, геоботанических и других видов обследований являющихся информационной базой охраны земель. На материалах Ростовской области анализируется качество кадастровой информации и возможность ее использования в построении ГИС управления охраной земель. Сформулирована система требований к содержанию тематических информационных слоев циифровой топографической основы этой системы.

Ключевые слова: кадастр недвижимости; геоинформационная система; мониторинг; мелиорируемые земли.

The problems of the nowadays conditions of planning and cartographic materials, data of soil analysis, geobotanic surveys and other types of information as a base for land protection are examined in the article. By the example of the Rostov region authors analyzed the quality of inventory information and the possibility of its using for the development of the GIS-based land conservation management. The system requirements for the content of thematic information layers of digital topographic base of this system are presented.

Key words: real estate cadastre; GIS; monitoring, reclaimed lands.

Исходная информация о состоянии и использовании земельных ресурсов формируется из материалов различного рода обследований и отчетности совмещенной с планово-картографическим материалом. Итоговым документом информации обеспечивающей реализацию задач системы охраны земельных ресурсов является кадастр недвижимости. Состояние исходной информации во многом определяет степень эффективности управленческих решений по осуществлению мероприятий по охране и рациональному использованию земель. В настоящее время планово-картографические материалы, материалы почвенных, геоботанических и других видов обследований нуждаются в обновлении. По данным содержащимся в Докладах о состоянии и использовании земель в Ростовской области имеется планово-картографический материал масштаба 1:25 000 съемки 1976-1986 гг. - 57,6\%,
1986-1990 гг. — 31,5\%, 1991-1995 гг. $11,8 \%$, который не может служить актуализированным доброкачественным материалом для решения задач управления земельными ресурсами [1].

Планово-картографический материал масштаба 1:10 000 съемки 1991-1995 гг. имеется на площадь 1080,89 тыс. га, что составляет $10,7 \%$ от общей площади области. Требуется создание цифровой картографической основы на всю территорию области, для земель поселений масштаба 1:2 000, для межселенных территорий масштаба 1:10 000 и масштаба 1:25000.

Материалы почвенного обследования проведенного до 1989 года имеются на 98,3\% площади земель сельскохозяйственного назначения. После 1990 года почвенные обследования земель сельскохозяйственного назначения проведены в Октябрьском, МатвеевоКурганском, Неклиновском, Куйбышевском 
районах на общей площади 254,43 тыс. га, или $3,14 \%$ площади земель сельскохозяйственного назначения. Требуется корректировка материалов почвенного обследования на 8098,36 тыс. га - вся площадь земель сельскохозяйственного назначения.

Данные геоботанических обследований являются основой качественной характеристики природных кормовых угодий. Материалы геоботанического обследования проведенного до 1988 года имеются на 99,8\% площади кормовых угодий. После 1995 года геоботаническое обследование природных кормовых угодий в области не проводилось. Требуется первичное обследование кормовых угодий на площадь 2425,17 тыс. га [1].

Сложившаяся ситуация требует срочных мер по проведению систематических мониторинговых исследований земель для выработки решений по улучшению условий их использования, предупреждению и устранению негативных процессов.

Принятие в 2005 году постановления правительства Российской Федерации утвердившее подпрограмму «Создание системы кадастра недвижимости (2006-2012 годы)» как составной части программы автоматизации ведения государственного земельного кадастра и государственного учета объектов недвижимости, с учетом последующих изменений, определило общую направленность работ в данной сфере [2].

В процессе разработки программы рассматривались два варианта создания государственного кадастра недвижимости. Первый вариант базировался на переходе к централизованному ведению государственного кадастра недвижимости на уровне органов кадастрового учета субъектов Российской Федерации по единому регламенту. По второму варианту создание и ведение государственного кадастра недвижимости должно базироваться сразу на федеральном уровне. В результате проработок был принят второй вариант, так как он исключает возможность ведения двойного учета объектов недвижимости, обеспечивает более полный контроль деятельности органов кадастрового учета, упрощает процедуры межведомственного информационного обмена и обработки экстерриториальных запросов на предоставление сведений об объектах кадастрового учета независимо от места их нахождения.

C момента принятия подпрограммы прошло более пяти лет. По официальным данным в настоящее время только 7,7\% дел, находящихся в архивах организаций технической инвентаризации, переведены в электронный вид. Для создания государственного кадастра недвижимости Федеральной службе государственной регистрации, кадастра и картографии необходимо провести инвентаризацию и ввести в государственный кадастр недвижимости сведения о более чем 42 млн. земельных участков и 70 млн. иных объектов недвижимости.

Создание ведомства, организационно объединившее кадастровую деятельность, правовое и картографическое обеспечение (Федеральная служба государственной регистрации, кадастра и картографии - Росреестр) до сих пор не обеспечило объединения информационных ресурсов. Сведения об объектах недвижимости содержатся в базах данных систем государственного земельного кадастра, технического учета объектов градостроительной деятельности, а также водного, лесного и других природно-ресурсных кадастров. Отсутствие современной цифровой картографической основы при проведении государственного кадастрового учета земельных участков создает проблемы с определением и согласованием границ земельных участков, что является негативным фактором при регистрации права собственности и иных вещных прав на землю.

В Ростовской области в 2010 году при проведении работ по повышению качества информации в базе данных выполнены работы по исправлению 2322 ошибочных записей (в местоположении, категории земель, разрешенном использовании) в земельных участках в соответствии с протоколом технических ошибок в семантической части БД ГКН. В рамках исполнения приказа Росреестра от 23.11.2010 г. №618 «Об организации работ по повышению качества данных единого государственного реестра прав и государственного кадастра недвижимости» по результатам верификации исправлены ошибки в 2830 земельных участках. В процессе текущей работы выявлены и устранены ошибки некорректного внесения сведений о местоположении 226187 земельных участков (в том числе 
ошибки переноса информации из ПК ЕГРЗ в АИС ГКН), ошибки пространственных данных о границах земельных участков - 46327 [3].

Фрагментарность и раздробленность информационной базы о состоянии и использовании земель свидетельствуют о серьезных пробелах методологии построения системы кадастра недвижимости.

Не претендуя на полный и всесторонний анализ методологических проблем кадастра недвижимости в данной статье мы попытаемся рассмотреть возможности использования ГИС-технологий в организации учета мелиорированных земель как составной части целостной информационной системы обеспечения управления земельными ресурсами.

Ведение кадастра недвижимости предусматривает создание системы формирования и учета единых объектов недвижимого имущества, при котором особое внимание уделяется топографическому материалу, являющемуся основой для всех объектов. Формирование единого объекта предполагает включение в него земельного участка в установленных границах и расположенных на нем зданий, сооружений, улучшений, а также вида и субъекта права.

Вся топографическая подоснова должна быть доступной для работы с ней в интерактивном режиме: подсчёт площадей, возможность изменения, добавления части графических данных на план, добавление или удаление характеристик объектов местности. Это возможно лишь в том случае, когда данные хранятся в векторном виде. Векторный формат данных позволяет хранить не только графическую часть, но и семантическую, т. е. к каждому векторному объекту привязана информация о его характеристиках. Это позволит формировать сложносоставные объекты, примером которого и является единый объект недвижимости.

Наиболее выгодное и целесообразное хранение векторной топографической информации должно быть реализовано путём создания единого хранилища векторной топоосновы. Современные компьютерные средства позволяют это осуществить на основе распределенного хранения логически единой базы пространственных данных. Для этого используют идеологию географических информационных систем (ГИС).

Геоинформационные системы сочетают в себе хорошо отработанные технологии реляционных СУБД и компьютерную графику высокого класса в целях управления информацией, описывающей земную поверхность либо относящуюся к ней. ГИС позволяют обрабатывать разнообразные типы данных об объектах либо характеристиках земной поверхности - координаты, формы, связки (пространственная информация), описательные сведения и цифры (непространственная информация). Все многообразие данных интегрируется в единую логическую модель. После этого интерактивные, базирующиеся на графике инструменты обеспечивают управление данными, их корректировку, создание запросов, анализ и вывод результатов, как в компьютерном, так и в традиционном виде [5].

Большинство инструментальных ГИС представляют в распоряжение пользователя довольно широкие возможности по обработке и анализу данных. В том числе возможности импорта/экспорта пространственных и атрибутивных данных в различные широко распространенные форматы; возможности реализации средств работы с реляционными базами данных; возможности по импорту данных с систем GPS и полевых накопителей; возможности по наложению карт, пространственному анализу, поиску объектов по адресам и анализу сетевых структур.

На основе инструментальной ГИС многие фирмы-производители реализуют полный технологический цикл работ для картографического производства, включающий: сбор и обработку данных полевой съемки, обработку данных ДДЗ, ввод графической и семантической информации, формирование исходных цифровых карт и семантических баз данных, анализ и интерпретацию исходной информации, получение тематических карт, оформление и печать картографического материала.

При реализации кадастровой системы могут быть добавлены модули, отвечающие за оперативное обновление кадастровой информации, ведение дежурной кадастровой карты, оформление и печать правоустанавливающих документов, проведение анализа земельных участков с целью оценки простран- 
ственного расположения в зависимости от определенных условий, а также модули, отвечающие за экономическую оценку земли.

Областей применения ГИС существует великое множество, и число их будет расти. Одна из наиболее востребованных и перспективных областей применения ГИС для целей кадастра и землеустройства является тематическое картографирование, т. е. создание тематических карт и атласов, обновление карт, оперативное картографирование, а также информационное обеспечение хозяйственной деятельности в регионах и городах, экологического мониторинга и рационального использования природных ресурсов.

В кадастре Российской Федерации картографические документы используются как носители первичной информации о земельных участках и как вспомогательные документы для пространственного отражения их месторасположения. Поэтому повышение законодательного статуса кадастровой картографической информации, утверждение картографических документов как обязательных в составе документов ГКН - обязательное требование, без выполнения которого невозможно эффективное использование кадастровой информации в реализации экономической и правовой составляющих земельных отношений (учёт объектов недвижимости, исчисление платежей за землю, установление залоговых ставок, регистрация прав на земельные участки и др.).

В последние годы успешно внедряется информационно-справочная функция ГИС, обеспечивающая, например, интерактивную реализацию запросов пользователя на получение пространственной кадастровой информации. Так, на сайте Росреестра размещена интерактивная кадастровая карта, обеспечивающая пользователей графической информацией о кадастровом делении территории, поставленных на кадастровый учет участках, их целевом назначении, кадастровой стоимости. Вместе с тем, объемы тематической информации, обеспечивающей взаимосвязь кадастрового учета с учетом качественных характеристик земель и использование ее для разработки проектных решений и задач по охране земель крайне ограничены.

Для эффективного управления важное значение имеет прогноз последствий прини- маемых решений, который может быть выполнен, на основе имитационного моделирования. В связи с этим, наряду с информационно-справочной функцией, требует развития и функция моделирования ГИС. Наличие имитационных, расчетных и других моделей в составе системы управления позволит оперативно анализировать несколько сценариев развития территории

Наиболее ценным видом земель используемых для производства сельскохозяйственной продукции являются мелиорированные угодья. По данным Росреестра в пользовании сельскохозяйственных товаропроизводителей находится 9,04 млн. га мелиорированных земель, в том числе 4,25 млн. га орошаемых и 4,79 млн. га осушенных с общей балансовой стоимостью систем всех форм собственности более 340 млрд. руб., в том числе федеральной собственности - 142,8 млрд. руб.

Мелиорированные земли занимают 8\% от общей площади пахотных угодий и позволяют производить около $15 \%$ валовой продукции, до $70 \%$ овощей, весь рис, более $20 \%$ грубых и сочных кормов и много другой продукции.

За последние годы в результате общего производственного спада из сельскохозяйственного оборота выбыло и переведено в немелиорированные угодья 2,2 млн. га, в том числе 1,9 млн. га орошаемых. Из общей площади орошаемых земель более 860 тыс. га имеют неудовлетворительное мелиоративное состояние, из них на 330 тыс. га наблюдается недопустимое залегание уровня грунтовых вод, на 260 тыс. га - засоление почв, на 270 тыс. га имеет место совместное проявление этих негативных процессов. Более половины оросительных систем нуждаются в проведении работ по реконструкции [1].

Наличие мелиорируемых земель обуславливает необходимость ведение мелиоративного кадастра, где содержатся как сведения о количестве и качестве орошаемых и осушаемых земель, так и технические показатели оросительных и осушительных систем. Наличие орошаемых и осушаемых земель усложняют работу при ведении кадастра недвижимости. Орошаемые земли учитывают с более высокой точностью и детально определяют качество каждого земельного участка. Ирригационная подготовка обходится доро- 
го, оросительная вода для сельскохозяйственного производства представляет огромную ценность. Поэтому их учет должен основываться на точных планово-картографических данных. В районе орошаемых земель ведется также кадастр оросительных систем. Между ним и кадастром недвижимости существует тесная связь, так как при составлении паспортов на оросительные системы используют данные кадастра недвижимости.

При ведении кадастра одним из главных инструментов получения такой информации должен быть мониторинг земель. Мониторинг мелиорированных земель (MМ3) представляет собой систему непрерывного слежения за параметрами состава, свойств и режимов почв, оросительных, дренажных, грунтовых (подземных) вод и водоприемника, границах мелиоративной системы и прилегающих территорий [4].

Мониторинг мелиорированных земель является составной частью Государственного мониторинга земель РФ и имеет общие объекты наблюдений с Государственной системой учета вод и Государственным мониторингом подземных вод. Мониторинг распространяется на орошаемые и осушаемые земли, независимо от их правового режима и характера использования, а также другие категории земель в границах мелиоративной системы или в зоне ее влияния.

Целью ведения мониторинга является наблюдение за состоянием земель для своевременного выявления деградации и загрязнения мелиорируемых почв, их оценки, предотвращения и устранения последствий негативных процессов, обеспечения экологической безопасности производственной деятельности на мелиорируемых землях и осуществления своевременных и эффективных мероприятий по охране мелиорируемых и прилегающих к ним территорий, а также водоприемников дренажного стока.

Задачи мониторинга заключаются в:

- получении своевременной и достоверной информации о состоянии мелиорируемых земель и прилегающих территорий, качестве оросительных, сбросных, грунтовых, дренажных вод, а также показателях технического состояния оросительных и осушительных систем;

- обеспечении пользователей на всех уровнях управления своевременной и текущей, ретроспективной и прогнозной информацией, характеризующей состояние мелиоративных земель и прилегающих к ним территорий, качество оросительных, сбросных, грунтовых, дренажных вод, а также показателях технического состояния оросительных и осушительных систем;

- разработке мероприятий (эксплуатационных, производственно-технологических и строительных) по окультуриванию мелиорируемых почв, предотвращению их деградации и загрязнения их дренажными и сбросными водами;

- оценке эффективности осуществляемых мероприятий по мелиорации земель, охране водных и земельных ресурсов мелиоративных систем и прилегающих территорий.

Мониторинг мелиорированных земель подразделяется на федеральный, региональный и локальный уровень ведения. Объектом MМЗ являются почвы, грунтовые, дренажные, оросительные и сбросные воды и гидротехнические сооружения в границах мелиоративной системы, а также водоприемники и прилегающие территории.

Содержание мониторинга мелиорированных земель определяют данные тематических съемок, обследований и режимных наблюдений, фиксирующих дискретные значения параметров состава, свойств и режимов объектов мониторинга в границах хозяйственных, природных, природно-техногенных и административно-территориальных участков суши.

При ведении мониторинга необходимо учитываются и постоянно уточняются границы полей, севооборотов, участков с группой близких по водопотреблению или устойчивости к переувлажнению культур, орошаемых (осушаемых) массивов, землевладений, землепользований, населенных пунктов, земель запаса, природоохранного, оздоровительного, рекреационного назначения, земель лесного и водного фонда, береговой линии водоприемника в паводковой и меженный период, а также бассейнов рек и озер.

Объект мелиорации представляет собой управляемую природно-техническую систему. Под управлением понимается постоянное обслуживание и поддержание в рабочем состоянии гидротехнических сооружений. 
Отсутствие управления приводит к потере объектом мелиорации работоспособности и деградации природной среды. Одной из мер поддержки аграрного сектора является оптимизация землепользования, в основе которой лежит информация о состоянии земельных ресурсов. Поэтому использование ГИС-технологий в гидромелиорации представляется весьма перспективным.

Проблемами и перспективами применения геоинформационных систем в мелиоративной науке и практике занимались многие организации и отдельные исследователи. Практическая реализация научных решений в основном осуществлялась на базе пакета ArcCIS Desktop, INTERGRAPH-Micro Station и MapInfo. Проведённый анализ показывает, что использование геоинформационных систем включало решение задач и кадастра недвижимости. Поэтому необходимо разработать элементы технологии ведения кадастра мелиорируемых земель на основе имеющихся ГИС. При этом основное внимание необходимо уделить картографическому обеспечению. Изучение картографического материала мелиорируемых земель Ростовской области показало, что существуют только схемы ирригационной сети по филиалам и системам, поэтому в качестве цифровой основы необходимо выбрать топографическую карту территории.

Топографическая информация используется для отображения положения объекта недвижимости в границах района. Цифровая топографическая основа является официальной государственной информацией и предназначается для создания и ведения государственного кадастра в автоматизированной информационной системе земельных служб.

Цифровая топографическая основа должна состоять из трёх базовых и нескольких тематических информационных слоев.

Первый базовый информационной слой содержит информацию о координатах геодезической сети и задает метрическое пространство района мелиорируемых земель. Второй базовый слой содержит информацию о координатах границ и кадастровых номеpax земельных участков. Третий базовый информационный слой содержит векторную цифровую карту естественной гидрографической сети (реки, ручьи) и искусственных сооружениях (водохранилище, водоподающие межхозяйственные и магистральные каналы, головные и перекачивающие насосные станции, подпорные и регулирующие сооружения), а также массивов мелиорируемых земель при минимальном объеме топографической информации.

Количество тематических слоев государственного кадастра на начальном этапе разработки системы не устанавливается. В тематических слоях могут отражаться административные и территориальные границы землепользований, почвенные разновидности, уровень грунтовых вод, эколого-экономическое состояние земель и т. д. Развитие информационной базы может потребовать новых и новых слоев.

Состав информации должен быть минимально необходимым для поддержания кадастровой информации в актуальном состоянии и обеспечения выполнения задач охраны земель. В основном это контуры объектов недвижимости, необходимые для понимания положения объекта в пространстве и его качественные характеристики необходимые для разработки и принятия управленческих решений.

\section{Литература}

1. Доклад о состоянии и использовании земель в Ростовской области в 2009 году. Управление Федеральной службы государственной регистрации, кадастра и картографии по Ростовской области [Электронный ресурс] / Росреестр. - Режим доступа: http://www. rosreestr.ru, свободный. - Загл. с экрана.

2. Постановление правительства Российской Федерации от 13.09.2005 №560 «Создание системы кадастра недвижимости (20062012 годы)» [Электронный ресурс] / Росреестр. - Режим доступа: http://www.rosreestr. $\mathrm{ru}$, свободный. - Загл. с экрана.

3. Постановление Администрации Ростовской области от 13.07.06 №265 «Об утверждении мероприятий по созданию системы кадастра недвижимости (2006-2011 годы) в Ростовской области» [Электронный ресурс] / Сайт правительства РО. - Режим доступа: http://www.donland.ru, свободный. - Загл. с экрана.

4. Ткачева О. А., Мещ̧анинова Е. Г., Ку- 
лиш Л. П. Эколого-мелиоративный мониторинг земельных ресурсов. // Экология и безопасность жизнедеятельности: VIII междунар. науч.-практ. конф: сб. статей. - Пенза: РИО ПГСХА, 2008. - С. 106-108.

5. Ткачева О. А., Плаксиикий Е. П. Геоинформационные системы в государственном управлении земельными ресурсами. // ИнПоступила в редакциию новационное развитие агропромышленного комплекса и аграрного образования: материалы междунар. науч.- практ. конф., посвящ. 80-летию ФГБОУ ВПО «Бурятская государственная сельскохозяйственная академия им. В. Р. Филлипова». - Улан-Удэ: Изд-во БГСХА им. В. Р. Филлипова, 2011. - С. 223-227.

19 сентября 2012 г.

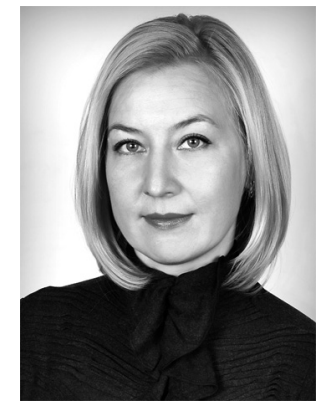

Ольга Александровна Ткачева - кандидат сельскохозяйственных наук, доцент, профессор кафедры «Кадастр и мониторинг земель» Новочеркасской государственной мелиоративной академии.

Olga Aleksandrovna Tkacheva - Ph.D., Candidate of Agricultural Sciences, professor at the «Cadastre and Land Monitoring» department of Novocherkassk State Land Reclamation Academy.

346428 , г. Новочеркасск, ул. Пушкинская, 111

111 Pushkinskaya st., 346428, Novocherkassk, Rostov reg., Russia

Тел.: +7 (8635) 27-96-30; e-mail: allesgut75@mail.ru

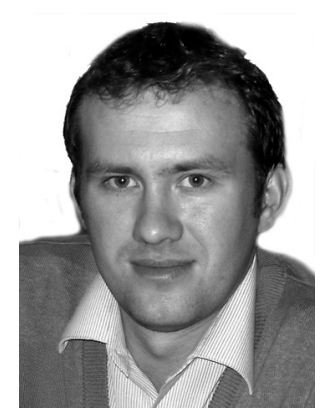

Сергей Алексеевич Тарасов - преподаватель Новочеркасского колледжа промышленных технологий.

Sergey Alekseyevich Tarasov - tutor at the Novocherkassk College of the Industrial Technologies. 